\title{
Characterizing and Quantifying Anthocyanins in Red Pears and the Effect of Light Quality on Fruit Color
}

\author{
Maria Claudia Dussi ${ }^{1}$ and David Sugar ${ }^{2}$ \\ Department of Horticulture, Oregon State University, Cowallis, OR 97331 \\ Ronald E. Wrolstad \\ Department of Food Science and Technology, Oregon State University, Cowallis, OR 97331 \\ Additional index words. Pyrus communis, Rosaceae, chromaticity
}

\begin{abstract}
The anthocyanin in 'Sensation Red Bartlett' pear skin was characterized and quantified, and the effect of light quality on fruit color development was evaluated. Anthocyanin concentration was related to fruit chromaticity values. Pigments were analyzed using high-performance liquid chromatography (HPLC) and thin-layer chromatography (TLC). One of two spots detected in the TLC chromatogram did not change color with molybdate sprays, indicating the possible presence of peonidin. HPLC analysis confirmed the presence of a major and a minor pigment, which co-eluted with cyanidin 3-galactoside and peonidin 3-galactoside. Monomeric anthocyanins in the pear skin extract were $6.83 \mathrm{mg} / 100 \mathrm{~g}$ of fruit peel. To study light quality, gelatin filters allowing passage of different wavelengths of-light were attached over the exposed side of 'Sensation Red Bartlett' pears 1 month before harvest. Chromaticity was recorded before the filters were attached and after their removal at harvest using the Commission Internationale del'Eclairage $\left(L^{*}, a^{*}\right.$, and $\left.b^{*}\right)$ color space coordinates. Following color measurements, anthocyanin was extracted from individual skin disks. Skin beneath all filters yielded less hue than the control. Wavelengths that transmit above $600 \mathrm{~nm}$ had the largest effect on chroma, a*, and $b^{*}$ values. Fruit wrapped in aluminum foil to obscure all light had the highest luminosity. Wavelengths from 400 to $500 \mathrm{~nm}$ gave darker, less chromatic, and redder pear fruit. All treatments yielded higher anthocyanin content than the control. There was a tendency toward increased anthocyanin content with longer wavelengths. The simple linear regression of the $\log$ anthocyanin content on $L^{*}$ value and $\left(a^{*} / b^{*}\right)^{2}$ provided an $R^{2}=0.41$.
\end{abstract}

The general pattern of anthocyanin distribution in red pears involves a nonpigmented epidermis and one or two additional nonpigmented layers, lying above two to five layers containing anthocyanins (Dayton, 1966). An exception is 'Starkrimson', a mutation of 'Clapp's Favorite', where 95\% of the color is due to anthocyanin in the epidermal layer (Dayton, 1966; Francis 1970). The gene or genes responsible for anthocyanin development in 'Max Red Bartlett' and 'Seckel' are carried in cells of the second histogenic layer, and this is probably also true for 'Rosired Bartlett' and 'Royal Red Hardy' (Dayton, 1966).

Pigments causing red coloration in pears are mainly anthocyanins. Those previously identified are cyanidin-3-galactoside, and cyanidin-3arabinoside (Francis, 1970). Both Pomoideae genera, Malus and Pyrus, contain cyanidin-3-galactoside which is absent from the other subfamilies of Rosaceae. Thus, it would be unlikely from a taxonomic point of view that two mutants of pears would differ in their major pigment (Francis, 1970; Timberlake and Bridle, 197 1). However, they might differ in the minor pigments. In contrast to apple, in which there is a notable presence of acylated pigments, these pigments are practically irrelevant in pears (Mazza and Miniati, 1993). Redelinghuys et al. (1973) identified cyanidin 3-galactoside and peonidin 3-galactoside in the epidermis of a red mutant of 'Williams Bon Chrétien' . Compared with other fruit, the concentration of anthocyanins in pear peels is distinctly lower, ranging from 5 to $10 \mathrm{mg} / 100 \mathrm{~g}$ of fresh weight (Macheix et al., 1990; Mazza and Miniati, 1993).

Received for publication 23 Jan. 1995. Accepted for publication 28 Apr. 1995. Oregon Agricultural Experiment Station technical paper no. 10,736. The cost of publishing this paper was defrayed in part by the payment of page charges. Under postal regulations, this paper therefore must be hereby marked advertisement solely to indicate this fact.

'Current address: Facultad de Ciencias Agrarias, Universidad National de Comahue, CC 85, (8303) Cinco Saltos, Rio Negro, Argentina.

${ }^{2}$ Southern Oregon Research and Extension Center, 569 Hanley Rd., Medford, OR 97502.
Biosynthesis of anthocyanins in plant tissues either requires, or is enhanced by light (Mancinelli, 1985). Siegelman and Hendricks (1958) reported that red color in apples requires light for its formation and is localized in the areas most exposed to the sun. Furthermore, anthocyanin content in the most exposed part of the fruit skin increases with light intensity up to at least $50 \%$ of full sunlight (Jackson, 1980). Formation of red anthocyanin in fruit is controlled by a high-energy photoreaction, with an action maximum at $650 \mathrm{~nm}$ (about 640 and $670 \mathrm{~nm}$ for Siegelman and Hendricks, 1958), a subsidiary one at 430 to $480 \mathrm{~nm}$, and by a subsequent photoreaction with an action maximum near $655 \mathrm{~nm}$ (Downs et al., 1965). The optimum wavelength for anthocyanin synthesis in harvested apples is $440 \mathrm{~nm}$ and red light was additive (Bishop and Klein, 1975). Light of wavelengths from 280 to 320 nm (UV-B) is highly effective in stimulating anthocyanin synthesis and exerts a synergistic effect when applied simultaneously with red light (Arakawa et al., 1985). Kubo et al. (1988) noticed that the rapid increase of anthocyanin formation in attached apples after bagging was prevented when UV cut-off filters were used. Dependence on certain light qualities for anthocyanin formation differs among cultivars, as does their responsiveness to white light (Arakawa et al., 1986; Arakawa, 1988).

Environmental and cultural factors influence fruit color development. Temperature and light are two environmental factors important for red pigment development in fruit (Saure, 1990; Singha et al., 1991a). Knowledge of the role of these factors in the control of anthocyanin biosynthesis is particularly valuable because they can be used for practical control of fruit quality and market value. The objectives of this study were to characterize and determine total monomeric anthocyanins in red pears, evaluate the effects of light quality on color in 'Sensation Red Bartlett' pears, and to relate anthocyanin concentration in fruit peels to fruit chromaticity values. 


\section{Materials and Methods}

\section{Characterization and quantitation of anthocyanins}

Peels from the exposed surface of 'Sensation Red Bartlett' pears grown in Medford, Ore., were used for this study. After harvest, peel disks $16 \mathrm{~mm}$ in diameter were removed, frozen in liquid nitrogen and stored at $-40 \mathrm{C}$. To prepare an aqueous extract, the frozen peels were shattered to a fine powder and blended with liquid nitrogen. Powdered sample $(51.2 \mathrm{~g})$ was mixed with $70 \mathrm{ml}$ of acetone and stored overnight at 5C (Wrolstad et al., 1990). The sample was filtered on a Buchner funnel, and the filter cake residue re-extracted with $30 \mathrm{ml}$ of $30 \%$ aqueous acetone. Filtrates were combined, shaken in a separatory funnel with $240 \mathrm{ml}$ chloroform, and stored overnight at 5C to allow a clean separation of the two phases (Wrolstad et al., 1990). The acetone-chloroform phase was discarded and the aqueous portion was made up to $100 \mathrm{ml}$ with distilled water.

Sample preparation for TLC and HPLC analysis of anthocyanins. PVPP (Polyclar AT; GAF Corp., N.Y.) was hydrated in water and left to settle overnight. The PVPP was poured in a Buchner funnel lined with Whatman no. 1 filter paper and the aqueous solution of the pear skins was applied, trying to avoid cracking the filter pad. The PVPP was then washed with water until the eluate was colorless. Pigments adsorbed onto PVPP were recovered with $200 \mathrm{ml} \mathrm{MeOH}$ in $2 \mathrm{ml} \mathrm{HCl}(1 \%$ methanolic $\mathrm{HCl})$ and centrifuged for a cleaner separation (Wrolstad et al., 1982). The anthocyanin extract was concentrated to dryness on a rotary evaporator (water bath temperature, 35C; vacuum, $736 \mathrm{~nm} \mathrm{Hg}$ ). The pigment concentrate was dissolved in $2 \mathrm{ml}$ of $1 \%$ methanolic $\mathrm{HCl}$ and $1 \mathrm{ml}$ was applied to a $20 \times 20-\mathrm{cm} \times 25-\mathrm{mm}$ cellulose TLC plate to develop the first dimension for $3 \mathrm{~h}$ in 25 acetic acid : 3 concentrate $\mathrm{HCl}: 72$ water $(\mathrm{AHW})(\mathrm{v} / \mathrm{v})$ solvent. The plate was allowed to air dry to remove the solvent and then sprayed with a saturated solution of ammonium molybdate adjusted to $\mathrm{pH} 2$ with $2 \mathrm{~N} \mathrm{HCl}$ and filtered (Wrolstad et al., 1982). A similar plate was prepared in which the first dimension was developed in AHW, and after air-drying, the second dimension was developed for $6 \mathrm{~h}$ in $2 \mathrm{n}$-pentanol : 1 acetic acid : 1 water (PAW) (v/v). This was also sprayed as before (Wrolstad and Struthers, 1971; Wrolstad et al., 1982).

For the HPLC sample, the extract was concentrated to dryness on the rotary evaporator as described above, but in this case the pigment concentrate was redissolved with $3 \mathrm{ml}$ of $4 \%$ phosphoric acid and filtered for HPLC. Cranberry juice cocktail (Ocean Spray, purchased locally), for which the anthocyanins have been thoroughly characterized, was used as a reference (Hong and Wrolstad, 1990). The cranberry cocktail solution was absorbed onto an activated $\mathrm{C} 18$ Sep-Pak. The cartridge was washed with $0.01 \%$ $\mathrm{HCl}$, and pigments were eluted with $0.01 \% \mathrm{HCl}$ methanol. The methanolic extract was then evaporated to about $1 \mathrm{ml}$. The isolate was redissolved in 4\% phosphoric acid and filtered for HPLC (Hong and Wrolstad, 1990). Cranberry cocktail and pear skin extracts mixed in different proportions, as well as each extract separately, were injected in the HPLC to characterize the anthocyanins in pear skins.

Liquid chromatography (Series 400; Perkin-Elmer) was performed under the following conditions: Supelcosil LC-18 fitted with ODS-10 Micro-Guard column; mobile-phase solvent: (A) $100 \%$ acetonitrile and (B) $8.4 \%$ acetonitrile, $8.4 \%$ acetic acid, $8.5 \%$ phosphoric acid. The following program was used: isocratic elution with $100 \%$ B from 0 to 5 min, linear gradient to $94 \%$ B from 5 to $20 \mathrm{~min}$, isocratic elution from 20 to $25 \mathrm{~min}$ and $100 \% \mathrm{~B}$ from 25 to $30 \mathrm{~min}$. The flow rate was $1.0 \mathrm{ml} \cdot \mathrm{min}^{-1}$, with an injection volume of $50 \mathrm{ml}$. The column was at room temperature.

Determination of anthocyanin pigment content. Monomeric anthocyanin pigment content was determined on aqueous extracts using a $\mathrm{pH}$ differential method (Wrolstad, 1976). The extract was divided into two samples. The first sample was diluted $5 \mathrm{x}$ with $\mathrm{pH}$ 1.0 buffer ( $2 \mathrm{ml}$ of sample to $10 \mathrm{ml}$ of buffer) so that the absorbance at $510 \mathrm{~nm}$ was <1.0. The $\mathrm{pH} 1.0$ buffer contained $125 \mathrm{ml} 0.2 \mathrm{~N} \mathrm{KCl}$ and $385 \mathrm{ml} 0.2 \mathrm{~N} \mathrm{HCl}$, was adjusted to $\mathrm{pH} 1.0$, and was diluted to 1:1 with water. The second sample was diluted with $\mathrm{pH} 4.5$ buffer as with $\mathrm{pH} 1.0$. The $\mathrm{pH} 4.5$ buffer contained $400 \mathrm{ml} 1 \mathrm{M}$ sodium acetate and $240 \mathrm{ml} 1 \mathrm{~N} \mathrm{HCl}$, was adjusted to $\mathrm{pH} 4.5$, and was diluted 1:1 with water. Turbidity (haze) was corrected by subtracting the absorbance at $700 \mathrm{~nm}$ from the absorbance at $510 \mathrm{~nm}$, the wavelength of maximum absorbance. Finally, the difference in absorbance (A) at $510 \mathrm{~nm}$ (corrected for haze) between $\mathrm{pH} 1.0$ and 4.5 samples was calculated. The anthocyanin pigment concentration (as cyanidin-3-galactoside) was determined by the following formula (Wrolstad, 1976): anthocyanin pigment $\left(\mathrm{mg} \cdot\right.$ liter $\left.^{-1}\right)=\mathrm{A} \times$ $\mathrm{MW} \times \mathrm{DF} \times 103 / \varepsilon \times \mathrm{L}$. For cyanidin-3-galactoside $\varepsilon=30,200$ (solvent: $1 \% \mathrm{HCl} / \mathrm{MeOH}$ ) and $\mathrm{MW}=445.2 ; \mathrm{L}=$ pathlength = 1.0; $\mathrm{DF}=$ dilution factor $=5$. The content of anthocyanin in the pear skins were expressed as mg cyanidin-3-galactoside/100 $\mathrm{g}$ of pear peels.

\section{Light quality}

Fruit color measurements of 'Sensation Red Bartlett' pears were taken in Medford, Ore., on 12-year-old trees grafted on Pyrus calleryana rootstock. Five fruit per treatment were chosen from the periphery of four trees. One month before harvest, the 8-mmdiameter measuring area of a Minolta CR-200b portable tristimulus calorimeter was placed at the midpoint between the stem and calyx of the sun-exposed surface of each fruit, and chromaticity was recorded in Commission Internationale de l'Eclairage (CIELAB) $\mathrm{L}^{*}, \mathrm{a}^{*}$, and $\mathrm{b}^{*}$ color spacecoordinates (Hunter, 1975; Singha et al., $1991 \mathrm{a}, 1991 \mathrm{~b})$. The meter was calibrated at illuminant condition $\mathrm{C}$ $(6774 \mathrm{~K})$ with a white standard before use (Minolta calibration plate CR.A43). L* represents the lightness of colors from 0 to 100 , being small for dark colors and large for light colors. The $a^{*}$ value is negative for green and positive for red. The $b^{*}$ value is negative for blue and positive for yellow. Both $\mathrm{a}^{*}$ and $\mathrm{b}^{*}$ scales range from

Table 1. Changes in chromaticity values (A) of 'Sensation Red Bartlett' pear surfaces measured 1 month before harvest and at harvest.'

\begin{tabular}{|c|c|c|c|c|c|}
\hline Treatmenty & $\Delta$ Hue angle & $\Delta$ Chroma & $\Delta \mathrm{L}^{*}$ & $\Delta \mathrm{a}^{*}$ & $\Delta \mathrm{b}^{*}$ \\
\hline Control & $7.92 \mathrm{a}$ & $11.15 \mathrm{ab}$ & $1.73 \mathrm{~cd}$ & $8.01 \mathrm{a}$ & $7.93 \mathrm{a}$ \\
\hline $400-500 \mathrm{~nm}$ & $3.67 \mathrm{c}$ & $7.88 \mathrm{c}$ & $1.37 \mathrm{~cd}$ & $6.27 \mathrm{c}$ & $4.98 \mathrm{~b}$ \\
\hline $500-600 \mathrm{~nm}$ & $6.73 \mathrm{ab}$ & $8.05 \mathrm{c}$ & $1.87 \mathrm{bc}$ & $6.10 c$ & $5.62 b$ \\
\hline$>700 \mathrm{~nm}$ & $4.12 \mathrm{bc}$ & $8.37 \mathrm{c}$ & $0.56 \mathrm{~d}$ & $6.75 b c$ & $5.11 \mathrm{~b}$ \\
\hline Opaque & $3.84 \mathrm{c}$ & $9.43 b c$ & $3.59 \mathrm{a}$ & $7.82 \mathrm{ab}$ & $5.44 \mathrm{~b}$ \\
\hline
\end{tabular}

${ }^{2}$ Mean separation within columns by LSD $(\mathrm{P}=0.05)$, each value is an average of 18 to 20 measurements.

'The treatments were a control, gelatin filters with spectral-transmittance at different wavelengths, and total opaque (fruit wrapped with aluminum foil). 
-60 to 60 . After fruit color was measured, $1.5-\mathrm{cm}$ square gelatin filters of different wavelengths (Eastman Kodak Company, 1981) were attached over the sun-exposed fruit surface. The treatments were control (without filter), total opaque (aluminum foil wrapped fruit), and filters with spectral-transmittance wavelengths from 400 to $500 \mathrm{~nm}, 500$ to $600 \mathrm{~nm}$ and above $700 \mathrm{~nm}$. At harvest, after filter removal, chromaticity was measured again. Following color measurements, disks $16 \mathrm{~mm}$ in diameter, corresponding to the location in the fruit skin where the filters were placed, were frozen in liquid nitrogen and stored at $-40 \mathrm{C}$ until needed.

Each disk was extracted overnight at $5 \mathrm{C}$ in $2 \mathrm{ml}$ of methyl alcohol containing $1 \% \mathrm{HCl}$. The extracts were placed in a rotary shaker in the dark for $2 \mathrm{~h}$, then filtered on a Buchner funnel and the filtrates were made up to $10 \mathrm{ml}$ with methyl alcohol containing $0.01 \% \mathrm{HCl}$. The extracts were centrifuged for $1 \mathrm{~min}$ at $8000 \mathrm{rpm}$ in microfilterfuge tubes. Absorbance was measured using a Bausch \&Lomb Spectronic 2000 spectrophotometer. Anthocyanin absorbance was obtained from (A530 - A700) and its concentration (as cyanidin-3-galactoside) was determined.

The data were analyzed using SAS General Linear Models procedure (SAS Institute, Cary, N.C.) based on a randomized block design with four blocks (trees) and six treatments. The analysis of variance was done for the differences in chromaticity (A) between the last measurement and the first one for hue angle $\left(\tan ^{-1} \mathrm{~b}^{*} / \mathrm{a}^{*}\right)$, chroma $\left(\left(\mathrm{a}^{*} 2+\mathrm{b}^{*} 2\right)^{1 / 2}\right), \mathrm{L}^{*}, \mathrm{a}^{*}$, and $\mathrm{b}^{*}$. Anthocyanin content among treatments was compared using Fisher's protected LSD. Data were log-transformed for analysis. The relationships of anthocyanin concentration to $\mathrm{L}^{*}, \mathrm{a}^{*}$, and $\mathrm{b}^{*}$ values were studied in the control samples of the measurement at harvest using a variety of regression models.

\section{Results and Discussion}

\section{Characterization and quantitation of anthocyanins}

Two spots corresponding to anthocyanin pigments were detected in one- and two-dimensional cellulose TLC chromatograms (data not shown). After molybdate sprays, one spot became purple and the other remained red. This suggests that red pear skins contain cyanidins (Francis, 1970) and peonidins (Redelinghuys, 1973), which do not change color with molybdate sprays (Wrolstad et al., 1982). A yellow spot was also found that could be due to another phenolic compound such as quercetin, found in appreciable amounts in apple peels (Timberlake and Bridle, 1971).

HPLC chromatography of pear skin anthocyanins showed two distinct peaks. The largest peak co-eluted with cyanidin 3-galactoside, the main anthocyanin found in red pear and apple skins. This confirms the findings of Francis (1970) Timberlake and Bridle (1971), and Redelinghuys et al. (1973). Based on total peak area, the relative percentage of cyanidin 3-galactoside was $63 \%$ and the retention time was $7.4 \mathrm{~min}$. The second largest peak co-eluted with peonidin 3-galactoside and had a retention time of $13 \mathrm{~min}$. The relative percentage of peonidin 3-galactoside based on total peak area was $18 \%$. These findings and the results of the TLC analysis confirm the presence of peonidin and agree with Redelinghuys et al. (1973) who identified peonidin 3-galactoside as a minor pigment in the epidermis of a red mutant of 'Williams Bon Chrétien'.

Determination of anthocyanin pigment content. Total monomeric anthocyanin in red pear skins was $6.83 \mathrm{mg} / 100 \mathrm{~g}$ of fruit skins. This value corresponds with the range of 5 to $10 \mathrm{mg} / 100 \mathrm{~g}$ of fresh weight cited by Macheix et al. (1990) in red pear peels. According to Francis (1970) in certain varieties of pear with red skins, only $10 \%$ to $50 \%$ of the epidermal or hypodermal cells contain anthocyanic pigments. That might explain in part the distinctly lower values of anthocyanin concentration in pear skin than those observed in other fruit.

\section{Light quality}

All treatments yielded less change in hue than the control, especially at wavelengths between' 400 to $500 \mathrm{~nm}$, above $700 \mathrm{~nm}$, and total opaque (Table 1). Wavelengths that transmitted above $600 \mathrm{~nm}$ had the largest effect on chroma and were not significantly different $(P>0.05)$ than the control, but differed from the filters that transmit above $700 \mathrm{~nm}$. This was also true for the change in a* and $b^{*}$ values (chroma is a function of both). This suggests that wavelengths between 600 to $700 \mathrm{~nm}$ affected chroma, resulting in more chromatic, more vivid colors. This wavelength range also gave a large change in $\mathrm{L}^{*}$ values (lighter colors) (Table 1). It has previously been shown that fruit red color formation due to anthocyanin is controlled by a high-energy photoreaction with an action maximum between 640 and $670 \mathrm{~nm}$ (Siegelman and Hendricks, 1958).

All treatments yielded higher anthocyanin content than the control, although differences among treatments were not significant (Table 2). There was a tendency toward increased anthocyanin production or retention with longer wavelengths, especially above 600 and $700 \mathrm{~nm}$. Aluminum-wrapped fruit had the highest luminosity, while wavelengths from 400 to $500 \mathrm{~nm}$ gave darker, less chromatic fruit. Down et al. (1965) found a subsidiary wavelength range between 430 to $480 \mathrm{~nm}$ affected anthocyanin formation. Furthermore, Bishop and Klein (1975) stated that the optimum wavelength for anthocyanin synthesis in harvested apples

Table 2. Anthocyanin content of the skins of 'Sensation Red Bartlett' pear surfaces.

${ }^{\bar{x}}$ Mean separation within columns by LSD $(\mathrm{P}=0.05)$. Each value is an average of at least four extractions.

'The treatments were a control, gelatin filters with spectral-transmittance at different wavelengths, and total opaque (fruit wrapped with aluminum foil).

Table 3. Coefficient of determination $\left(R^{2}\right)$ for selected regression models relating chromaticity values to anthocyanin content in fruit peels of 'Sensation Red Bartlett' nears.

\begin{tabular}{ll}
\hline \hline Variable & \\
\hline$a^{*}$ & $R^{2}$ \\
$b^{*}$ & 0.05 \\
$L^{*}$ & 0.38 \\
Hue angle $\left(\tan ^{-1} b^{*} / a^{*}\right)$ & 0.41 \\
Chroma $\left[\left(a^{* 2}+b^{* 2}\right)^{1 / 2}\right]$ & 0.34 \\
$a^{*} / b^{*}$ & 0.04 \\
$\left(a^{*} / b^{*}\right)^{2}$ & 0.39 \\
$L^{*}$ Hue angle & 0.41 \\
$L^{*}\left(a^{*} / b^{*}\right)$ & 0.42 \\
$L^{*}\left(a^{*} / b^{*}\right)^{2}$ & 0.44 \\
\end{tabular}

${ }^{2}$ Data were transformed to the log scale for analysis. 


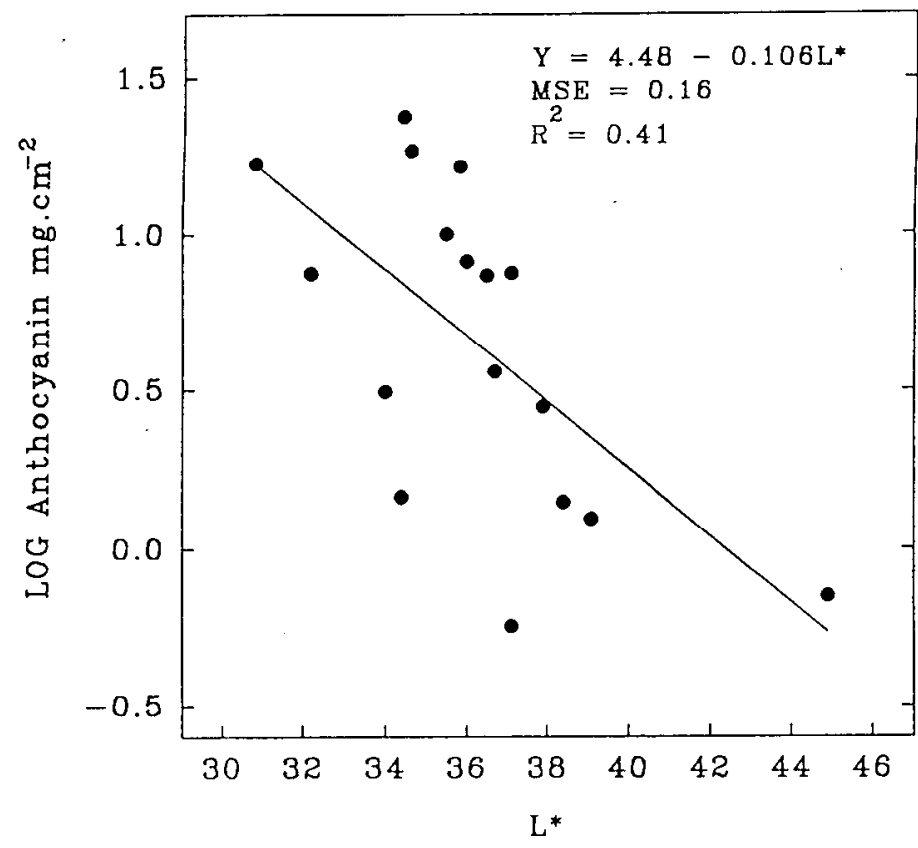

Fig. 1. Relationship between extractable anthocyanin and $\mathrm{L}^{*}$ values measured at harvest in 'Sensation Red Bartlett' pear peels.

was $440 \mathrm{~nm}$ and red light was additive.

Aluminum-wrapped fruit (opaque treatment) showed relatively high levels of anthocyanin (Table 2), small changes in hue angles, and redder fruit skins (Table 1). At the time the experiment was initiated, fruit were mature and probably a high level of anthocyanin was already present. Proctor and Lougheed (1976) found that bagging temporarily raises the level of phytochrome. Phytochrome, a pigment bound to a protein, is the photoreceptor in lightdependent anthocyanin synthesis. Saure (1990) stated that etiolated tissues contain more phytochrome than green tissues, and that light causes destruction of phytochrome. In contrast, for our control treatment, a pigment degradation process may explain the low anthocyanin content, change in hue angles, and yellower fruit (Chalmers et al., 1973). Saure (1990) noted that, although from the beginning of fruit development all apple cultivars are able to form anthocyanins if receiving sufficient light, they lose this capability at different stages of fruit growth. Therefore, anthocyanin synthesis in response to light is developmentally regulated (Proctor and Creasy, 197 1).

High hue angles could be due to degradation of anthocyanin and an increase in carotenoid formation. In 'Cox's Orange Pippin' apples, Knee (1972) showed that anthocyanin levels increased 3fold (4 to $12 \mathrm{mg} \cdot \mathrm{cm}^{-2}$ ) during ripening, while chlorophyll concentration fell 4-fold and carotenoid increased 4-fold. Light has been shown to enhance flavonoid production. Quercetin glycosides were twice as high in peels of 'Golden Delicious' on the sunny side of fruit as compared to the shaded side (Workman, 1963). This increase in flavonoid concentration was not accompanied by reddening and anthocyanin production (Lancaster, 1992).

Several linear models used to relate chromaticity coordinates to anthocyanin content gave poor to relatively satisfactory results (Table 3). The simple linear regression of the log anthocyanin content on $\mathrm{L}^{*}$ value (Fig. 1) and $\left(\mathrm{a}^{*} / \mathrm{b}^{*}\right)^{2}$ provided an $R^{2}$ of 0.41 .Precisionwas enhanced slightly when both terms were included in the model $\left(R^{2}=\right.$ 0.46). These results agree with the report of Singha et al. (1991a), although the coefficients of determination in their study were higher. A smaller number of samples was used in this work.
Wavelengths above $600 \mathrm{~nm}$ gave the largest change in chroma, $a^{*}$, and $b^{*}$ values. They had effects similar to the control but different from wavelengths above $700 \mathrm{~nm}$. Wavelengths from 400 to $500 \mathrm{~nm}$ gave darker, less chromatic and redder pear fruit. The change in hue was lower for all treatments vs. the control. Aluminum-wrapped fruit showed the greatest change in $\mathrm{L}^{*}$ value. All treatments yielded higher anthocyanin content than the control and there was a tendency toward increased anthocyanin content with longer wavelengths. Although the predominant anthocyanins and flavonoids in apples and pears have been characterized, their copigmentation interaction to produce red coloration and the moderating effect of carotenoid and chlorophyll on the perception of color need further investigation.

\section{Literature Cited}

Arakawa, O. 1988. Characteristics of color development in some apple cultivars: changes in anthocyanin synthesis during maturation as affected by bagging and light quality. J. Jpn. Soc. Hort. Sci. 57:373-380. Arakawa, O., Y. Hori, and R. Ogata. 1986. Characteristics of color development and relation between anthocyanin synthesis and phenylalanineammonia-lyase activity in 'Starking Delicious', 'Fuji' and 'Mutsu' apple fruits. J. Jpn. Soc. HortSci. 54:424-430.

Arakawa, O., Y. Hori, and R. Ogata. 1985. Relative effectiveness and interaction of ultraviolet-B, red and blue light in anthocyanin synthesis of apple fruit. Physiol. Plant. 64:323-327.

Bishop, R.C. and R.M. Klein. 197.5. Photo-promotion of anthocyanin synthesis in harvested apples. HortScience 10:126-127.

Chalmers, D.J., J.D. Faragher, and J.W. Raff. 1973. Changes in anthocyanin synthesis as an index of maturity in red apple varieties. J. Hort. Sci. 48:387-392.

Dayton, D.F. 1966. The pattern and inheritance of anthocyanin distribution in red pears. Proc. Amer. Soc. Hort. Sci. 89:110-116.

Downs, R.J., H.W. Siegelman, W.L. Butler, and S.B. Hendricks. 1965. Photoreceptive pigments for anthocyanin synthesis in apple skin. Nature 205:909-910.

Eastman Kodak Company. 198 1. Kodak filters for scientific and technical uses. 3rd ed. Kodak publication B-3, Cat. 1528108.

Francis, F.J. 1970. Anthocyanins in pears. HortScience 5:42.

Hong, V. and R.E. Wrolstad. 1990. Use of HPLC separation/photodiode array detection for characterization of anthocyanins. J. Agr. Food Chem. 38:708-715.

Hunter, R.S. 1975. The measurement of appearance. Wiley, New York. Jackson, J.E. 1980. Light interception and utilization by orchard systems. V. In: J. Janick (ed.). Horticultural reviews. vol 2. AVI Publ. Co., Westport. Conn.

Knee, M. 1972. Anthocyanin, carotenoid, and chlorophyll changes in the peel of Cox's Orange Pippin apples during ripening on and off the tree. J. Expt. Bot. 23: 184-196.

Kubo, Y., S. Taira, S. Ishio, A. Sugiura, and T. Tomana. 1988. Color development of four apple cultivars grown in the Southwest of Japan, with special reference to fruit bagging. J. Jpn. Soc. Hort. Sci. 57: 191199.

Lancaster, J.E. 1992. Regulation of skin color in apples. Critical Rev. Plant Sci. 10:487-502.

Macheix, J.J., A. Fleuriet, and J. Billot. 1990. Fruit phenolics. CRC Press, Boca Raton, Fla.

Mancinelli, A.L. 1985. Light-dependent anthocyanin synthesis: a model system for the study of plant morphogenesis. Bot. Rev. 51:107-157.

Mazza, G. and E. Miniati. 1993. Anthocyanins in fruits, vegetables and grains. CRC Press, Boca Raton. Fla.

Proctor, J.T.A. and L.L. Creasy. 1971. Effect of supplementary light on anthocyanin synthesis in 'McIntosh' apples. J. Amer. Soc. Hort. Sci. 96:523-526.

Proctor, J.T.A. and E.C. Lougheed. 1976. The effect of covering apple: during development. HortScience 11:108-109.

Redelinghuys, H.J.P., B.H. Koeppen, and G.H. De Swardt. 1973. The anthocyanin in a South African red sport of Pyrus communis L. cv. 
Williams Bon Chrétien. Agrochemophysica 5:21-24.

Same, M.C. 1990. External control of anthocyanin formation in apple. Sci. Hort. 42:181-218.

Siegelman, H.W. and S.B. Hendricks. 1958. Photocontrol of anthocyanin synthesis in apple skin. Plant Physiol. 33:185-190.

Singha, S., T.A. Baugher, E.C. Townsend, and MC. D’Souza. 1991a. Anthocyanin distribution in 'Delicious' apples and the relationship between anthocyanin concentration and chromaticity values. J. Amer. Soc. Hort. Sci. 116:497499.

Singha, S., E.C. Townsend, and T.A. Baugher. 1991b. Relationship between visual rating and chromaticity values in 'Delicious' apple strains. Fruit Var. J. 45:33-36.

Timberlake, C.F. and P. Bridle. 1971. The anthocyanins of apples and pears: the occurrence of acyl derivatives. J. Sci. Food Agr. 22:509-513.
Workman, M. 1963. Color and pigment changes in Golden Delicious and Grimes Golden Delicious apples. Proc. Amer. Soc. Hort. Sci. 83:149161.

Wrolstad, R.E. 1976. Color and pigment analyses in fruit products. Oregon Agr. Expt. Sta. Bul. 624.

Wrolstad, R.E., J.D. Culbertson, C.J. Comwell, and L.R. Mattick. 1982. Detection of adulteration in blackberry juice concentrates and wines. J. Assn. Off. Anal. Chem. 65:1417-1423.

Wrolstad, R.E., G. Skrede, P. Lea, and G. Enersen. 1990. Influence of sugar on anthocyanin pigment stability in frozen strawberries. J. Food Sci. 55:1064-1065.

Wrolstad, R.E. and B.J. Struthers. 1971. Polyvinylpyrrolidone column chromatography of strawberry, rhubarb and raspberry anthocyanins. J. Chromatog. 55:405-408. 